\title{
Regenerative Limb Salvage: A Novel Technique for Soft Tissue Reconstruction of Pediatric Extremities
}

\author{
Fouad Saeg, BS ${ }^{1}$ Elvira N. Chiccarelli, MD² Hugo St. Hilaire, MD, DMD ${ }^{3}$ Frank H. Lau, MD, FACS 3
}

1 Tulane University School of Medicine, New Orleans, Louisiana

${ }^{2}$ Department of Pediatrics, Louisiana State University Health Sciences

Center New Orleans, New Orleans, Louisiana

${ }^{3}$ Division of Plastic and Reconstructive Surgery, Louisiana State

University Health Sciences Center New Orleans, New Orleans,

Louisiana

\author{
Address for correspondence Frank H. Lau, MD, FACS, Department of \\ Surgery, Louisiana State University Health Sciences Center New \\ Orleans, 1542 Tulane Ave, 7th Floor, New Orleans, LA 70112 \\ (e-mail: flau@lsuhsc.edu).
}

J Reconstr Microsurg Open 2020;5:e82-e89.

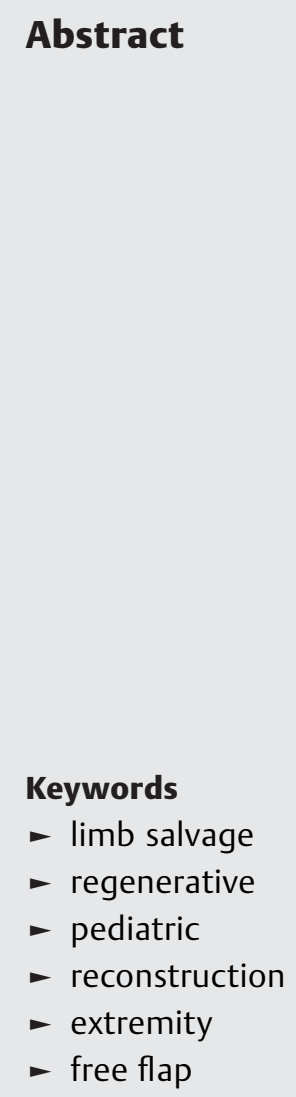

Background In complex extremity wounds, free flap-based limb salvage ( $f L S$ ) is the standard of care. However, fLS is resource- and cost-intensive, and the limited availability of pediatric microsurgical expertise exacerbates these challenges. Regenerative LS (rLS) addresses these barriers to care. The aim of this study was to quantify the efficacy, safety, and cost-effectiveness of rLS in complex pediatric extremity wounds.

Methods We conducted a retrospective cohort study of pediatric LS at a single hospital. Subjects were treated with $\mathrm{fLS}$ or $\mathrm{rLS}$ based on surgeon preference. Primary outcome measures were: definitive wound closure rates and time, rates of return to ambulation, number and length of procedures to achieve definitive closure, and rates of perioperative complications. Statistical analyses were performed utilizing the Wilcoxon Mann-Whitney $U$ test with statistical significance set at $p<0.05$.

Results Over a 2-year period, nine consecutive patients presented with complex extremity wounds requiring $\mathrm{fLS}(n=4)$ or $\operatorname{rLS}(n=5)$. Demographics and wound characteristics were similar between groups. Compared with $\mathrm{fLS}$, the rLS group achieved definitive wound closure $85.8 \%$ more quickly (13.8 vs. 97.5 days, $p<0.02$ ), required $64.5 \%$ less operative time $(132.6$ vs. 373.0 minutes, $p<0.02)$, had fewer perioperative complications ( 0 vs. 5 ), and required fewer intensive care unit stays ( 0 vs. 1.3 days).

Conclusion These data indicate that $\mathrm{rLS}$ is a safe and efficacious option in pediatric patients requiring soft tissue reconstruction for LS. Use of this novel technique can restore the reconstructive ladder, thereby expand patient access to pediatric LS while minimizing morbidity and reducing LS-related resource utilization.
Complex pediatric extremity wounds with osseous, tendon, or joint exposures are a rare yet devastating problem. As a key component of limb salvage (LS), soft tissue reconstruction is necessary to avoid osteomyelitis and tendon or joint rupture, which would result in disability or amputation. ${ }^{1}$
Presently, the dominant LS paradigm employs the reconstructive elevator wherein free flap-based LS (fLS) is the recommended first-line treatment paradigm. ${ }^{2,3}$ This paradigm developed due to the significantly higher failure rates for the lower "rungs" of the reconstructive ladder, such as received

June 7, 2020

accepted

August 2, 2020
DOI https://doi.org/

10.1055/s-0040-1718420.

ISSN $2377-0813$.
Copyright $\odot 2020$ by Thieme Medical

Publishers, Inc., 333 Seventh Avenue, New York, NY 10001, USA. Tel: +1(212) 760-0888.
License terms

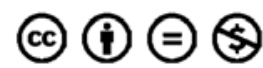


skin grafts and local flaps. ${ }^{4}$ However, fLS is resource-intensive and costly. ${ }^{5,6}$ Patients who do not live near a pediatric hospital may therefore not have access to fLS. From a technical perspective, pediatric fLS can be more difficult than in adults due to smaller vasculature, ${ }^{7-10}$ and the challenges of limiting postoperative activity and limb positioning in children. ${ }^{5}$

To overcome these challenges, our group developed a novel, regenerative LS (rLS) technique using dehydrated human amnion/chorion membrane (dHACM). ${ }^{11}$ In our pilot experience in adults, $86 \%$ of rLS patients were successfully reconstructed. The mechanism of action for DHACM is the gradual and sustained release of over 300 growth factors, antimicrobial peptides, and immunomodulatory and antiinflammatory molecules. rLS leverages dHACM to stimulate the growth of stable granulation tissue over exposed structures that traditionally do not generate significant granulation tissue, such as cortical bone stripped of periosteum, tendon missing paratenon, and/or joint articular capsules. Once a stable granulation base is regenerated, definitive closure is achieved with split-thickness skin grafts (STSG). ${ }^{11,12}$

Compared with adults, pediatric patients generally have greater regenerative potential. ${ }^{13}$ Given the success of rLS in adults, we extended the application of rLS to pediatric patients. The aim of this study was to quantify the efficacy, safety, and cost-effectiveness of rLS in complex pediatric extremity wounds in comparison to fLS. Despite our hospital's status as the largest volume, free-standing pediatric hospital in the state of Louisiana, the number of pertinent cases remained small, thus necessitating a retrospective study design.

\section{Methods}

\section{Study Design}

This was an institutional review board-approved, retrospective cohort study. The study population was comprised of pediatric patients (age $<18$ years) presenting to a single nonprofit children's hospital. Nine consecutive pediatric patients with complex extremity wounds required surgical intervention over a 2-year period (December 2014-December 2016). Based on surgeon preference, these patients underwent either free fLS or rLS.

Demographic variables collected for each case included age, sex, mechanism of injury, wound size, and the structures exposed. Operative variables of interest focused on the following: type of flap selection, operative time (minutes), total number of follow-up dHACM applications, total number of operations, and unplanned surgical intervention. Complications were defined as a total or partial flap loss, wound dehiscence, and any donor site morbidity. Postoperative variables included the number of pediatric intensive care unit (PICU) stays, inpatient hospital stays, and time to definitive wound closure (defined as complete wound closure without discharge). Primary outcome measures included length of intensive care stay, rate of peri- and postoperative complication, and time to definitive wound closure. Due to the small sample sizes of each group, nonparametric testing utilizing the Wilcoxon Mann-Whitney $U$ test was performed with statistical significance set at $p<0.05$ (SAS version 9.4).

\section{rLS Technique}

For rLS, the management algorithm consisted of initial excisional debridement of all contaminated, nonviable tissue followed by assessment of the size and location of exposed critical structures. The placement of dHACM (EpiFix; MiMedx Group Inc.) was custom fit and applied to exposed bone or tendon ( $\mathbf{- V i d e o} \mathbf{1})$, moistened with sterile saline, and bolstered with a nonadherent contact layer (Adaptic; Acelity). The bolster was secured with suture or surgical staples to avoid loss of the dHACM during outer dressing changes. The outer dressing material was customized to the anticipated amount of wound exudate. For less exudative wounds, moist-to-dry sterile gauze was applied and changed every 2 to 3 days. For more exudative wounds, a silver-impregnated absorbent dressing (Mepilex Ag; Mölnycke) was applied and changed after 7 days. Wounds were assessed weekly for infection and the generation of an adequate granulation base in the operating room. If needed, repeat debridement was performed, dHACM was reapplied, or definitive closure with an STSG and a negative pressure dressing bolster was performed.

\section{Video 1}

Application of dHACM. Online content including video sequences viewable at: https://www.thieme-connect. com/products/ejournals/html/10.1055/s-00401718420 .

\section{Results}

Patient demographics and wound characteristics were similar between groups. The mean ages were 11.7 years in rLS versus 9.7 years in fLS $(p=0.79)$. The mean wound size was $141.6 \mathrm{~cm}^{2}$ in rLS versus $154.0 \mathrm{~cm}^{2}$ in fLS $(p=0.56)$. All injuries were associated with exposed critical structures of the lower extremity, including exposed bone ( $\mathrm{rLS} n=1$, fLS $n=3$ ), exposed bone and tendon ( $\operatorname{lLS} n=1$, fLS $n=1$ ), exposed bone, tendon, and cartilage ( $\operatorname{rLS} n=1$, fLS $n=0$ ), exposed tendon only ( $\mathrm{rLS} n=1, \mathrm{fLS} n=0$ ), or exposed tendon and cartilage ( $\operatorname{rLS} n=1, \mathrm{fLS} n=0)$. The mean length of followup was 313.8 days (range: $54-498$ days) in rLS and 154.0 days (range: $21-306$ days) in fLS (-Table 1).

Overall, rLS patients required $64.5 \%$ less operative time than fLS patients (132.6 vs. 373.0 minutes, $p=0.016$; - Fig. 1A). The time to definitive wound closure was $85.8 \%$ shorter in rLS (13.8 vs. 97.5 days, $p=0.016$; - Fig. 1B). The mean number of dHACM applications in the rLS group was 1.40 (range: $1-2$ ).

rLS patients experienced no postoperative complications. In contrast, $75 \%$ of fLS patients experienced complications 
Table 1 Patient characteristics

\begin{tabular}{|c|c|c|c|}
\hline & rLS & fLS & $p^{a}$ \\
\hline Number & 5 & 4 & \\
\hline Gender (M:F) & $3: 2$ & $2: 2$ & \\
\hline Mean age $\pm S D, y$ & $11.7 \pm 5.4$ & $9.7 \pm 6.7$ & 0.794 \\
\hline $\begin{array}{l}\text { Mean duration of } \\
\text { follow-up, } d\end{array}$ & $\begin{array}{l}313.8 \pm \\
309.7\end{array}$ & $\begin{array}{l}154.0 \pm \\
134.1\end{array}$ & 0.556 \\
\hline $\begin{array}{l}\text { Mean wound } \\
\text { size } \pm S D, \mathrm{~cm}^{2}\end{array}$ & $\begin{array}{l}141.6 \pm \\
140.1\end{array}$ & $\begin{array}{l}154.0 \pm \\
131.4\end{array}$ & 0.556 \\
\hline \multicolumn{4}{|l|}{$\begin{array}{l}\text { Mechanism of } \\
\text { injury }\end{array}$} \\
\hline $\begin{array}{l}\text { Motor vehicle } \\
\text { collision }\end{array}$ & 1 & 0 & \\
\hline $\begin{array}{l}\text { Off-road vehicle } \\
\text { injury }\end{array}$ & 2 & 0 & \\
\hline $\begin{array}{l}\text { Lawn mower } \\
\text { injury }\end{array}$ & 1 & 2 & \\
\hline Gunshot wound & 1 & 0 & \\
\hline Tumor resection & 0 & 2 & \\
\hline \multicolumn{4}{|l|}{$\begin{array}{l}\text { Critical structures } \\
\text { exposed }\end{array}$} \\
\hline Bone & 1 & 3 & \\
\hline Bone + tendon & 1 & 1 & \\
\hline $\begin{array}{c}\text { Bone + ten- } \\
\text { don + cartilage }\end{array}$ & 1 & 0 & \\
\hline Tendon & 1 & 0 & \\
\hline Tendon + cartilage & 1 & 0 & \\
\hline
\end{tabular}

Abbreviations: $\mathrm{fLS}$, flap-based limb salvage; $\mathrm{rLS}$, regenerative limb salvage; SD, standard deviation.

Note: Nine patients underwent limb salvage. There were no significant age, gender, or wound size differences between the two groups.

${ }^{a}$ Statistical significance for Wilcoxon Mann-Whitney $U$ test at $0.05 \alpha$ level.
Table 2 Complications

\begin{tabular}{|l|l|l|}
\hline & rLS & $\mathrm{fLS}$ \\
\hline Any complication & 0 & 5 \\
\hline Total flap loss & - & 1 \\
\hline Partial flap loss & - & 1 \\
\hline Wound dehiscence & 0 & 1 \\
\hline Venous thrombosis & 0 & 1 \\
\hline Donor site complication & 0 & 1 \\
\hline Unplanned return to operating room & 0 & 2 \\
\hline Mean reoperative time \pm SD, min & 0 & $70.7 \pm$ \\
& & 8.96 \\
\hline
\end{tabular}

Abbreviations: $f L S$, flap-based limb salvage; rLS, regenerative limb salvage; SD, standard deviation.

Note: rLS produced fewer postoperative complications. rLS required fewer unplanned returns to the operating room and less reoperative time. However, numbers in the rLS group were too small for statistical comparison.

including flap loss, wound dehiscence, and venous thromboses. Furthermore, $50 \%$ of fLS patients required an unplanned return visit to the operating room ( $0 \%$ for $\mathrm{rLS}$ ). Additional operative time due to complications averaged 70.7 minutes in $\mathrm{fLS}$ (- Table 2).

No rLS patients required PICU admission, whereas fLS patients averaged 1.3 days for flap monitoring. In fLS $(n=4)$ patients, the free flaps used were vertical profunda artery perforator $(n=2)$, latissimus do.rsi $(n=1)$, and anterolateral thigh $(n=1)$ (-Table 3 ). By completion of follow-up, all patients $(100.0 \%)$ in both groups had resumed ambulation. None developed infection at any phase of treatment. Example rLS cases are presented below.
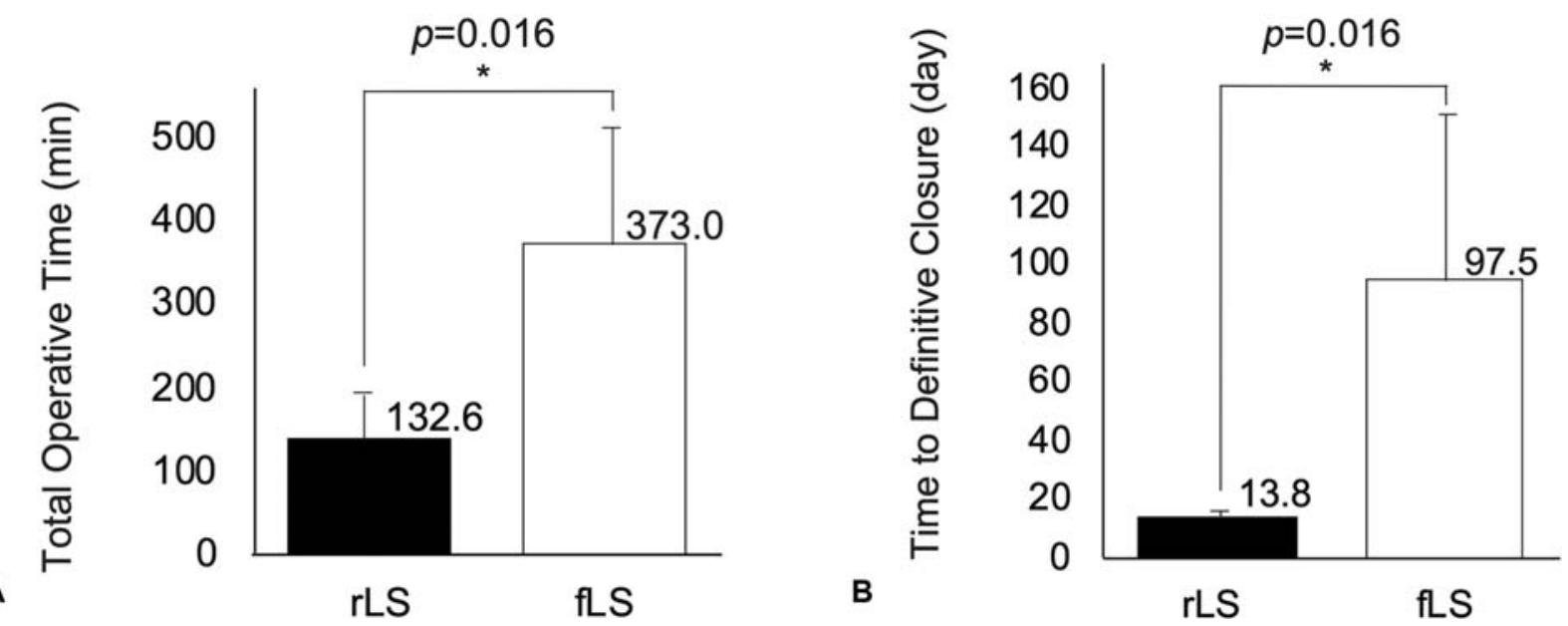

Fig. 1 (A) Total operative time. Mean operative times were 132.6 and 373.0 minutes in regenerative limb salvage (rLS) and flap-based limb salvage ( $f L S)$, respectively $(p=0.016)$. In rLS, the mean total operative time was reduced by $64.5 \%$ compared with fLS. *Statistical significance for Wilcoxon Mann-Whitney $U$ test set at $0.05 \alpha$ level. (B) Time to definitive reconstruction. Mean times to definitive wound closure were 13.8 and 97.5 days in $\mathrm{rLS}$ and $\mathrm{fLS}$, respectively $(p=0.016)$. In rLS, definitive reconstruction was achieved $85.8 \%$ faster than $\mathrm{fLS}$. ${ }^{\mathrm{S}} \mathrm{Statistical}$ significance for Wilcoxon Mann-Whitney $U$ test set at $0.05 \alpha$ level. 
Table 3 Comparison of operative outcomes

\begin{tabular}{|l|l|l|l|l|}
\hline & rLS & fLS & $p^{\text {a }}$ & \% change \\
\hline Mean PICU stay \pm SD, d & 0 & $1.3 \pm 0.6$ & & \\
\hline Mean inpatient hospital stay \pm SD, d & $9.4 \pm 4.5$ & $15.3 \pm 11.5$ & 0.564 & $-38.6 \%$ \\
\hline Flap selection & & & & \\
\hline VPAP & - & 2 & & \\
\hline LD & - & 1 & & \\
\hline ALT & - & 1 & & \\
\hline Mean dHACM application \pm SD & $1.40 \pm 0.55$ & - & & \\
\hline Mean operative time \pm SD, min & $132.6 \pm 84.9$ & $373.0 \pm 140.1$ & $0.016^{\text {a }}$ & $-64.5 \%$ \\
\hline Mean time to definitive wound closure \pm SD, d & $13.8 \pm 1.9$ & $97.5 \pm 76.3$ & $0.016^{\text {a }}$ & $-85.8 \%$ \\
\hline
\end{tabular}

Abbreviations: ALT, anterolateral thigh; dHACM, dehydrated human amnion/chorion membrane; fLS, flap-based limb salvage; LD, latissimus dorsi; PICU, pediatric intensive care unit; rLS, regenerative limb salvage; SD, standard deviation; VPAP, vertical profunda artery perforator.

Note: rLS requires significantly fewer PICU stays and fewer inpatient hospital stays. In rLS, operative time and time to definitive wound closure were significantly reduced by 64.5 and $85.8 \%$, respectively.

${ }^{a}$ Statistical significance for Wilcoxon Mann-Whitney $U$ test at $0.05 \alpha$ level.

\section{Case 1: Gustilo IIIB Open Tibial Fracture}

A 14-year-old boy presented with a Gustilo IIIB open tibial fracture of his left lower extremity following an off-road vehicle accident. He underwent excisional debridement and fracture stabilization with an external fixator ( - Fig. 2A). The exposed tibia was stripped of periosteum (-Fig. 2B). The cortex was burred to pinpoint bleeding and a single layer of dHACM was applied. After 1 week, adequate granulation tissue developed, and definitive closure with STSG was successful (-Fig. 2C). The wound completely healed in 3 weeks and remained stably closed at 18 months (-Fig. 2D, E).

\section{Case 2: Exposed Metatarsal Joint}

A 3-year-old boy presented with exposed metatarsal cartilage following a riding lawnmower accident ( - Fig. 3A, B). He underwent initial excisional debridement followed by one dHACM treatment, which yielded granulation tissue coverage of the exposed cartilage after 1 week. STSG with a negative pressure dressing bolster was used to achieve definitive coverage ( $\mathbf{- F i g}$. 3C). When the bolster was taken down on postoperative day 5 , a small area $\left(<0.1 \mathrm{~cm}^{2}\right)$ of exposed cartilage persisted ( - Fig. 3D). A second treatment of dHACM was applied. Two weeks later, the wound was fully healed. The wound remained stably closed at 2-month follow-up, and he resumed ambulation ( - Fig. 3E; - Video 2).

\section{Video 2}

Patient's return to ambulation at 2-month follow-up. Online content including video sequences viewable at: https://www.thieme-connect.com/products/ ejournals/html/10.1055/s-0040-1718420.

\section{Case 3: Multiple Areas of Exposed Bone and Tendon}

A 17-year-old girl presented with a complex open wound of her right lower leg and foot following a motor vehicle collision ( - Fig. 4A). After initial excisional debridement, examination revealed two areas of exposed bone and tendon. Exposed cortex was burred to pinpoint bleeding and one dHACM sheet was applied, followed by STSG a month later (-Fig. 4B, C). The wound remained stably closed at the 2month follow-up and the patient resumed ambulation (-Fig. 4D).

\section{Discussion}

A recent systematic review of over 1,300 adult fLS patients reported success rates ranging from 73 to $100 \%$, with a pooled rate of $92.7 \% .{ }^{14}$ In this study, we found that pediatric rLS and fLS both yielded 100\% reconstructive success and $100 \%$ return-to-ambulation. However, rLS was advantageous in several key areas, including shorter operative times, fewer operations, fewer complications, and the avoidance of PICU admission. Additional advantages of rLS include the option to apply dHACM in an outpatient setting and increased patient access to pediatric LS by removing the requirement for microsurgical expertise.

When limited to free flaps, the fLS paradigm is technically demanding, costly, and limits patient access. ${ }^{5,6}$ These barriers have spurred innovation in fLS to reduce the reliance on free tissue transfer, and recent, notable innovations include propeller flaps and keystone flaps. ${ }^{15-18}$ However, these innovations do not alter the dominance of the fLS paradigm.

In terms of technical challenges, consistent success at fLS requires microsurgical training and experience, as well as a sufficient case load to maintain those skills. In specific cases, achieving microvascular anastomosis outside the zone of injury can prove difficult. Our third case is one such example: the zone of injury extended from foot to groin (-Fig. 4). 

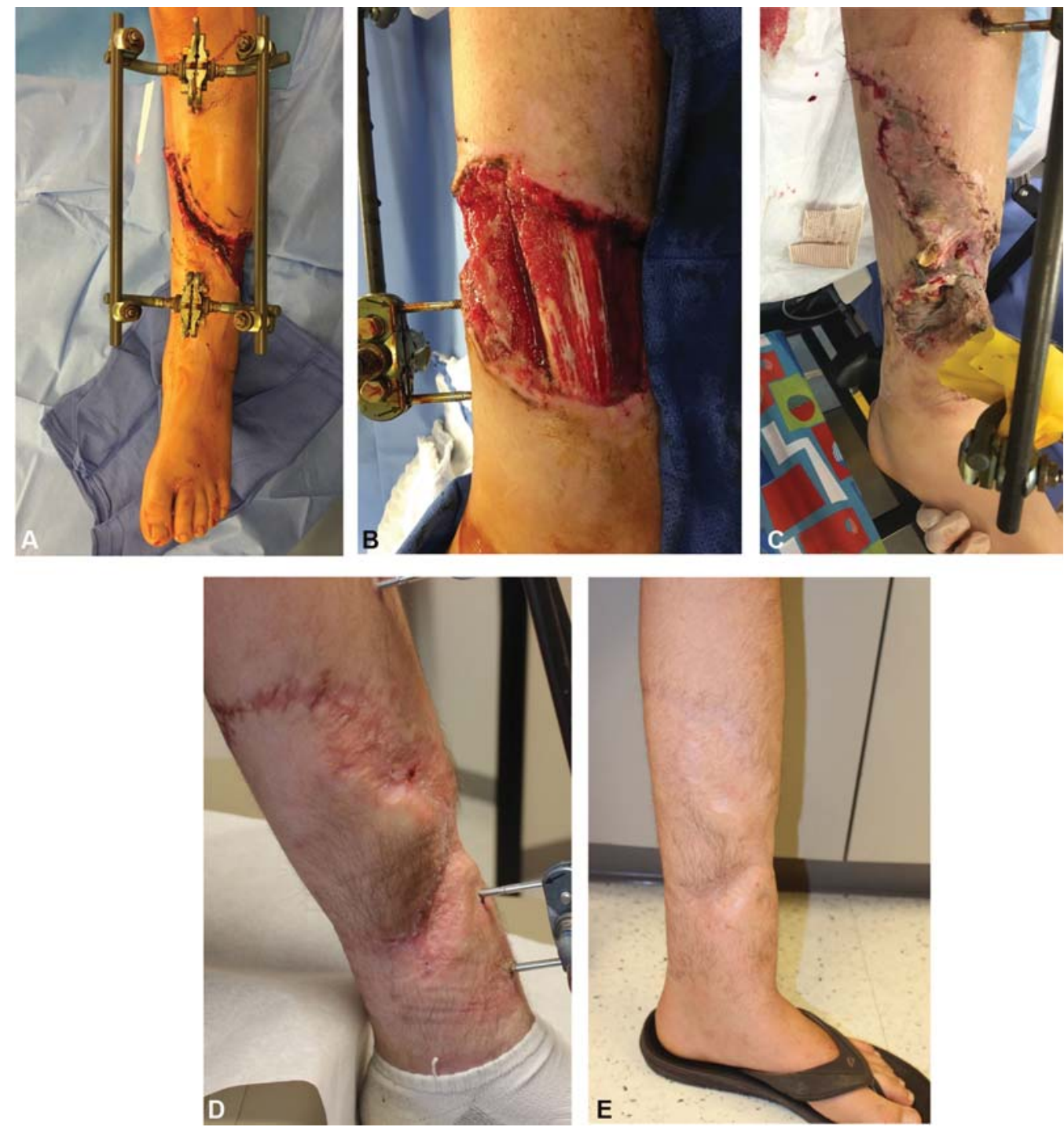

Fig. 2 Case 1: Gustilo IIIB open tibial fracture. A 14-year-old male underwent initial sharp debridement and stabilization of a Gustilo IIIB open tibial fracture with an external fixator (A). Exposed tibia without periosteum was covered by undermining of soft tissue envelope and advancing using tension sutures (B). A single dehydrated human amnion/chorion membrane (dHACM) was applied over the exposed anterior tibia, adequate granulation tissue developed, and split-thickness skin grafts (STSG) was successful (C). The wound completely healed in 3 weeks and remained stably closed at 18-month follow-up (D, E).

Alternatively, injuries such as those to the plantar surface often require ultra-thin flaps that may be unavailable given the growing epidemic of obesity. In the pediatric population, smaller vessel size and increased arterial spasm make free tissue transfer challenging even for experienced microsurgeons. ${ }^{7-10}$ Multiple studies have shown that anastomoses involving vessels with a diameter $<0.7 \mathrm{~mm}$ increase the risk of flap failure due to the technical difficulty. ${ }^{5,6,19}$ Furthermore, postoperative activity restrictions and positioning requirements are notoriously difficult to impose on pediatric patients, yet crucial for flap survival. In contrast, rLS does not require microsurgical expertise but also preserves all fLS options as reconstructive lifeboats.

fLS costs are high, with mean 2-year costs of $\$ 81,316$ and an estimated lifetime cost of over $\$ 200,000$ in pediatric patients. ${ }^{20}$ The Lower Extremity Assessment Project study found that fLS' high costs are partly due to prolonged hospital stays (range: 2-85 days), multiple surgical procedures (1-7 procedures), and frequent rehospitalization (60.7\% required readmission). ${ }^{21}$ We found similar patterns in the pediatric fLS patients in this study: they required significantly longer hospital stays, more surgical procedures, and experienced more perioperative complications. By requiring significantly fewer inpatient resources, rLS should yield cost savings.

Patient access to fLS is often limited because surgeons with the training, experience, and willingness to perform free-tissue transfers for trauma tend to cluster in urban environments and academic medical centers. ${ }^{22}$ The result is that LS candidates in low socioeconomic or rural areas may never be offered fLS due to the lack of hospitals offering specialty care. ${ }^{22}$ Pediatric LS candidates are further burdened by the sparsity of pediatric hospitals with microsurgical capabilities. Fewer than $15.0 \%$ of pediatric hospitals are 

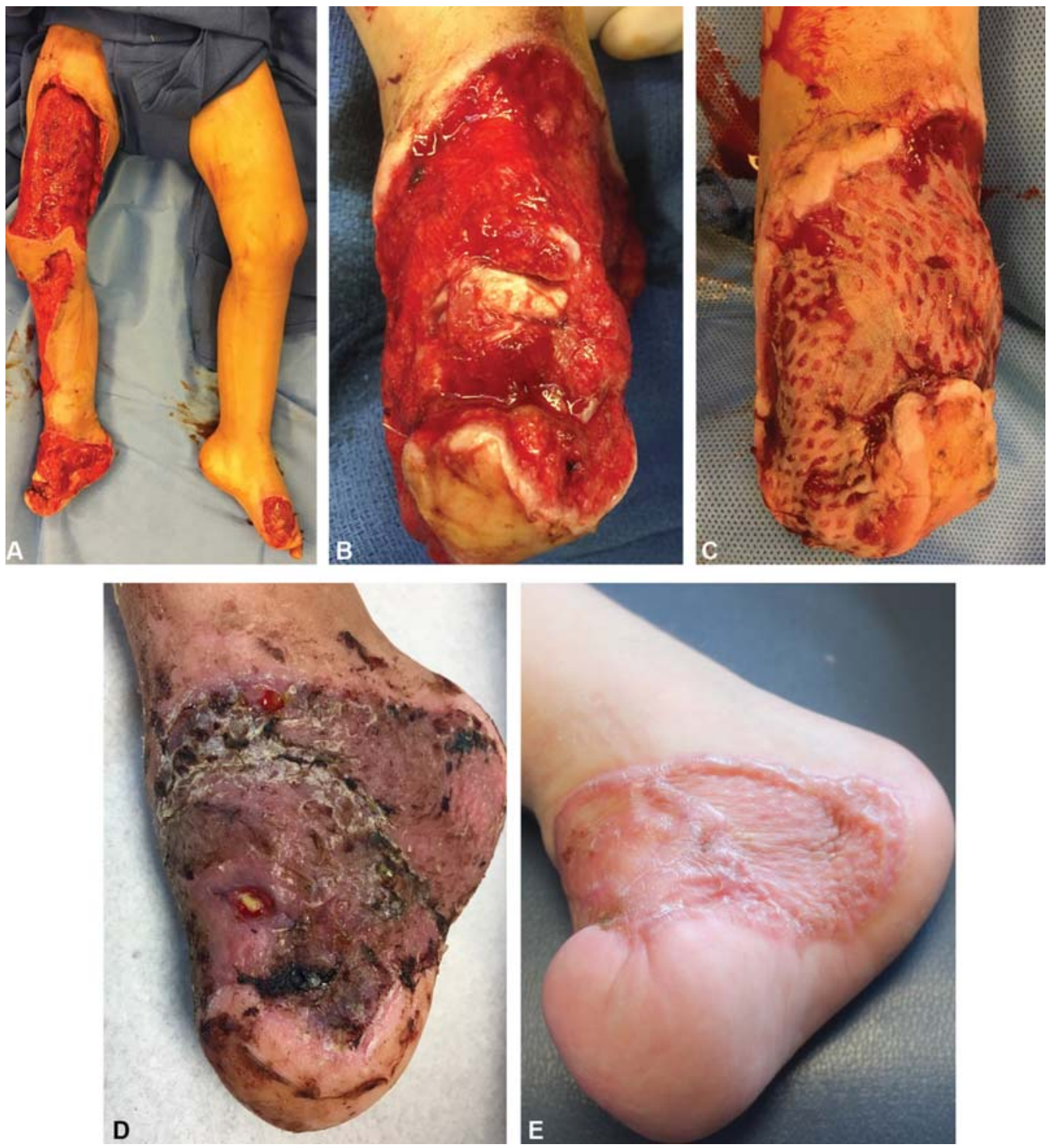

Fig. 3 Case 2: Exposed metatarsal joint. A 3-year-old male with exposed cartilage and tendon on bilateral feet following lawn mower injury. Regenerative limb salvage (rLS) was performed. He underwent debridement of all necrotic tissue (A, B). One dehydrated human amnion/chorion membrane (dHACM) treatment was performed followed by split-thickness skin graft (C). On postoperative day 5 , a small area $\left(<0.1 \mathrm{~cm}^{2}\right)$ of exposed cartilage persisted (D). A second treatment of AHACM was applied for definitive wound closure. Two weeks later, the wound was clean and fully healed with no palpable cartilage. The wound remained stably closed at 2-month follow-up and he has resumed ambulation (E).
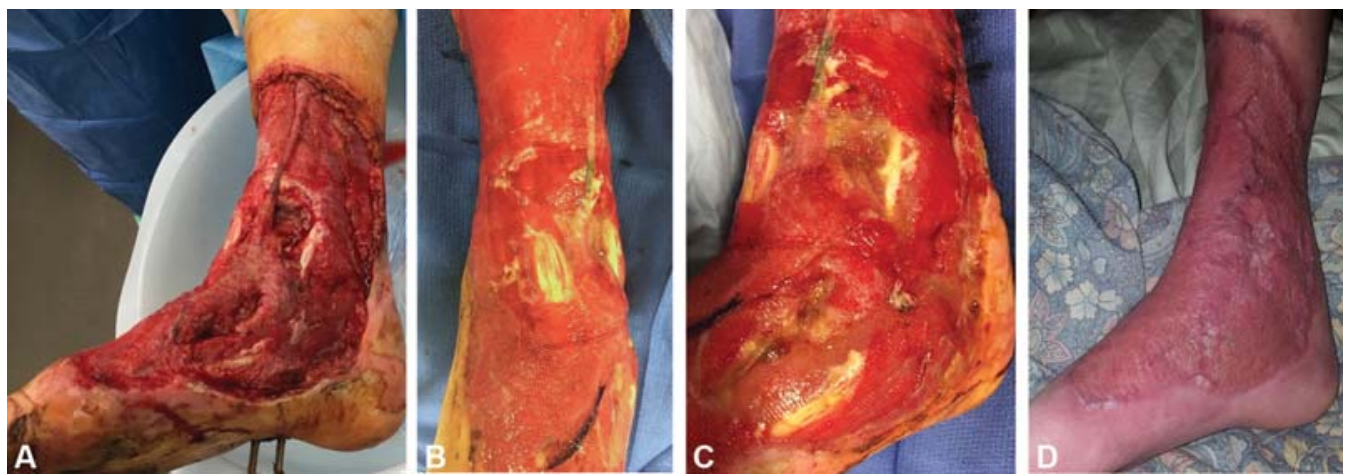

Fig. 4 Case 3: Multiple areas of exposed bone and tendon. A 17-year-old female presented following a motor vehicle collision with multiple areas of exposed bone and tendon on her right leg and foot (A). The medial leg and foot received a single dehydrated human amnion/chorion membrane (dHACM) treatment followed by split-thickness skin grafts (STSG) (B, C). The wound remained stably closed at 2-month follow-up and the patient resumed ambulation (D). 
considered high-volume centers $(>1,000$ pediatric surgical admissions per year). ${ }^{22}$ In fact, $71.0 \%$ of U.S. hospitals admit fewer than 250 pediatric surgery patients per year and, as a whole, see less than $20.0 \%$ of all pediatric plastic surgery cases nationwide. $^{22}$ The low pediatric LS volume feeds back to the technical challenges of fLS, as studies have shown that higher case volumes drive improved outcomes, especially in the pediatric population. ${ }^{22-28}$ Restoring the reconstructive ladder for LS would address these challenges.

Other non-fLS strategies are reported in the literature, such as the use of acellular wound matrices (AWMs) that serve as scaffolding for the ingrowth of granulation tissue. These matrices include collagen matrices, human acellular dermal matrices, and porcine urinary bladder matrices. ${ }^{29-38}$ We distinguish rLS from these strategies because dHACM functions not through scaffolding, but instead through the elution of $>300$ bioactive molecules that modulate inflammation, promote tissue regeneration, and fight infection. $^{39-41}$ Whereas we have experience no wound infections during the granulation tissue phase in any of our adult and pediatric rLS patients, the use of AWM for coverage of exposed bone has a 9 to $20.0 \%$ infection rate. ${ }^{42,43}$

Several limitations exist in this study. First, due to the low incidence of pediatric LS, the sample sizes were small and not adequately powered to detect many potentially significant differences between the two cohorts. Second, the retrospective nature of the study design suggests the possibility of selection bias. Third, our findings are limited to patients presenting to a single institution in an urban setting, and therefore limit the external validity of our results.

\section{Conclusion}

This study demonstrates that rLS is a safe and efficacious reconstructive option for pediatric LS patients. rLS patients achieved definitive closure more quickly than their fLS counterparts. Moreover, rLS patients experienced less operative time and required fewer surgeries, and therefore utilized fewer inpatient resources. Further studies are needed to establish the long-term impact rLS may have on the pediatric LS population and its' overall cost-utility relative to free flap reconstruction.

\section{Funding}

This work was supported by an LSUHSC Clinical Research Grant.

\section{Conflict of Interest}

None declared.

\section{References}

1 Koshy JC, Seruya M. Reconstructive algorithms in the pediatric population. J Surg Oncol 2016;113(08):940-945

2 Janis JE, Kwon RK, Attinger CE. The new reconstructive ladder: modifications to the traditional model. Plast Reconstr Surg 2011; 127(Suppl 1):205S-212S

3 Gottlieb LJ, Krieger LM. From the reconstructive ladder to the reconstructive elevator. Plast Reconstr Surg 1994;93(07):1503-1504
4 Pollak AN, McCarthy ML, Burgess ARThe Lower Extremity Assessment Project (LEAP) Study Group. Short-term wound complications after application of flaps for coverage of traumatic softtissue defects about the tibia. J Bone Joint Surg Am 2000;82(12): 1681-1691

5 Upton J, Guo L. Pediatric free tissue transfer: a 29-year experience with 433 transfers. Plast Reconstr Surg 2008;121(05):1725-1737

6 Canales F, Lineaweaver WC, Furnas H, et al. Microvascular tissue transfer in paediatric patients: analysis of 106 cases. Br J Plast Surg 1991;44(06):423-427

7 Ohmori K, Harii K, Sekiguchi J, Torii S. The youngest free groin flap yet? Br J Plast Surg 1977;30(04):273-276

8 Devaraj VS, Kay SP, Batchelor AG, Yates A. Microvascular surgery in children. Br J Plast Surg 1991;44(04):276-280

9 Sekiguchi J, Ohmori K. Youngest replantation with microsurgical anastomoses. Hand 1979;11(01):64-68

10 Moghari A, Emami A, Sheen R, O'Brien BM. Lower limb reconstruction in children using expanded free flaps. Br J Plast Surg 1989;42(06):649-652

11 Torabi R, Strong AL, Hogan E, et al. Bone and tendon coverage via dehydrated human amniotic/chorionic membrane and splitthickness skin grafting. J Reconstruct Microsurg Open 2016;1 (01):59-62

12 Zelen CM, Snyder RJ, Serena TE, Li WW. The use of human amnion/chorion membrane in the clinical setting for lower extremity repair: a review. Clin Podiatr Med Surg 2015;32(01): 135-146

13 Izadpanah A, Moran SL. Pediatric microsurgery: a global overview. Clin Plast Surg 2017;44(02):313-324

14 Saddawi-Konefka D, Kim HM, Chung KC. A systematic review of outcomes and complications of reconstruction and amputation for type IIIB and IIIC fractures of the tibia. Plast Reconstr Surg 2008;122(06):1796-1805

15 Pignatti M, Ogawa R, Hallock GG, et al. The "Tokyo" consensus on propeller flaps. Plast Reconstr Surg 2011;127(02):716-722

16 Khouri JS, Egeland BM, Daily SD, et al. The keystone island flap: use in large defects of the trunk and extremities in softtissue reconstruction. Plast Reconstr Surg 2011;127(03): 1212-1221

17 Bekara F, Herlin C, Mojallal A, et al. A systematic review and metaanalysis of perforator-pedicled propeller flaps in lower extremity defects: identification of risk factors for complications. Plast Reconstr Surg 2016;137(01):314-331

18 Nelson JA, Fischer JP, Brazio PS, Kovach SJ, Rosson GD, Rad AN. A review of propeller flaps for distal lower extremity soft tissue reconstruction: is flap loss too high? Microsurgery 2013;33(07): 578-586

19 Gilbert A. Reconstruction of congenital hand defects with microvascular toe transfers. Hand Clin 1985;1(02):351-360

20 Chung KC, Saddawi-Konefka D, Haase SC, Kaul G. A cost-utility analysis of amputation versus salvage for Gustilo type IIIB and IIIC open tibial fractures. Plast Reconstr Surg 2009;124(06): 1965-1973

21 MacKenzie EJ, Jones AS, Bosse MJ, et al. Health-care costs associated with amputation or reconstruction of a limb-threatening injury. J Bone Joint Surg Am 2007;89(08):1685-1692

22 Salazar JH, Goldstein SD, Yang J, et al. Regionalization of pediatric surgery trends already underway. Ann Surg 2016;263(06): 1062-1066

23 Lapcharoensap W, Gage SC, Kan P, et al. Hospital variation and risk factors for bronchopulmonary dysplasia in a population-based cohort. JAMA Pediatr 2015;169(02):e143676

24 Kastenberg ZJ, Lee HC, Profit J, Gould JB, Sylvester KG. Effect of deregionalized care on mortality in very low-birth-weight infants with necrotizing enterocolitis. JAMA Pediatr 2015;169 (01):26-32

25 Lui C, Grimm JC, Magruder JT, et al. The effect of institutional volume on complications and their impact on mortality after 
pediatric heart transplantation. Ann Thorac Surg 2015;100(04): 1423-1431

26 Evans C, van Woerden HC. The effect of surgical training and hospital characteristics on patient outcomes after pediatric surgery: a systematic review. J Pediatr Surg 2011;46(11):2119-2127

27 Committee on Trauma of the American College of Surgeons Regional Trauma Systems: Optimal Elements, Integration, and Assessment Systems Consultation Guide. 2008

28 McAteer JP, LaRiviere CA, Drugas GT, Abdullah F, Oldham KT, Goldin AB. Influence of surgeon experience, hospital volume, and specialty designation on outcomes in pediatric surgery: a systematic review. JAMA Pediatr 2013;167(05):468-475

29 Hutchison RL, Craw JR. Use of acellular dermal regeneration template combined with NPWT to treat complicated extremity wounds in children. J Wound Care 2013;22(12):708-712

30 Saab IR, Sarhane KA, Ezzeddine HM, Abu-Sittah GS, Ibrahim AE. Treatment of a paediatric patient with a distal lower extremity traumatic wound using a dermal regeneration template and NPWT. J Wound Care 2014;23(10):S5-S8. Doi: 10.12968/ jowc.2014.23.Sup10.S5

31 Herlin C, Louhaem D, Bigorre M, Dimeglio A, Captier G. Use of Integra in a paediatric upper extremity degloving injury. J Hand Surg Eur Vol 2007;32(02):179-184

32 Violas P, Abid A, Darodes P, Galinier P, de Gauzy JS, Cahuzac JP. Integra artificial skin in the management of severe tissue defects, including bone exposure, in injured children. J Pediatr Orthop B 2005; 14(05):381-384

33 Lee LF, Porch JV, Spenler W, Garner WL. Integra in lower extremity reconstruction after burn injury. Plast Reconstr Surg 2008;121 (04):1256-1262

34 Ellis CV, Kulber DA. Acellular dermal matrices in hand reconstruction. Plast Reconstr Surg 2012;130(05, Suppl 2):256S-269S
35 Sheridan RL, Choucair RJ. Acellular allogenic dermis does not hinder initial engraftment in burn wound resurfacing and reconstruction. J Burn Care Rehabil 1997;18(06):496-499

36 Barnett TM, Shilt JS. Use of vacuum-assisted closure and a dermal regeneration template as an alternative to flap reconstruction in pediatric grade IIIB open lower-extremity injuries. Am J Orthop 2009;38(06):301-305

37 Lattari V, Jones LM, Varcelotti JR, Latenser BA, Sherman HF, Barrette RR. The use of a permanent dermal allograft in fullthickness burns of the hand and foot: a report of three cases. J Burn Care Rehabil 1997;18(02):147-155

38 Menn ZK, Lee E, Klebuc MJ. Acellular dermal matrix and negative pressure wound therapy: a tissue-engineered alternative to free tissue transfer in the compromised host. J Reconstr Microsurg 2012;28(02):139-144

39 Maan ZN, Rennert RC, Koob TJ, Januszyk M, Li WW, Gurtner GC. Cell recruitment by amnion chorion grafts promotes neovascularization. J Surg Res 2015;193(02):953-962

$40 \mathrm{Koob}$ TJ, Rennert R, Zabek N, et al. Biological properties of dehydrated human amnion/chorion composite graft: implications for chronic wound healing. Int Wound J 2013;10(05):493-500

41 Koob TJ, Lim JJ, Massee M, et al. Angiogenic properties of dehydrated human amnion/chorion allografts: therapeutic potential for soft tissue repair and regeneration. Vasc Cell 2014;6(01):10

42 Graham GP, Helmer SD, Haan JM, Khandelwal A. The use of Integra ${ }^{\circledR}$ dermal regeneration template in the reconstruction of traumatic degloving injuries. J Burn Care Res 2013;34(02): 261-266

43 Valerio IL, Masters Z, Seavey JG, Balazs GC, Ipsen D, Tintle SM. Use of a dermal regeneration template wound dressing in the treatment of combat-related upper extremity soft tissue injuries. J Hand Surg Am 2016;41(12):e453-e460 